\title{
AS DESIGNAÇÕES PARA CAROLINA MARIA DE JESUS E QUARTO DE DESPEJO NA IMPRENSA DE 1960
}

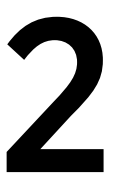

\section{LES DÉSIGNATIONS DE CAROLINA MARIA DE JESUS ET QUARTO DE DESPEJO DANS LA PRESSE DE 1960}

\section{BURANELLI, Gabriela Moreira}

Mestre em Linguística pela Universidade de Franca

E-mail: gabi_mburanelli@hotmail.com

ORCID ID: https://orcid.org/0000-0002-4656-7585

\section{BOCCHI, Aline Fernandes de Azevedo}

Doutora em Linguística pela Universidade Estadual de Campinas

Docente Pesquisadora do PPG Linguística da Universidade de Franca

E-mail: azevedo.aline@gmail.com

ORCID ID: https://orcid.org/0000-0003-4225-743X

\section{RESUMO}

Este artigo intenta compreender, a partir da luz teórica da Análise do Discurso Pecheutiana, os gestos de interpretação para Carolina Maria de Jesus na imprensa no ano de 1960, quando a autora lançou Quarto de Despejo: diário de uma favelada. Mulher negra, mãe, escritora, moradora da extinta Favela do Canindé e catadora de reciclagem, Carolina Maria de Jesus teve sua primeira obra traduzida em 14 idiomas e vendida em mais de 40 países. No Brasil, na época do lançamento de Quarto de Despejo, Carolina era designada pela imprensa nacional ora como "a favelada", ora como "escritora-favelada", o que dá a ver o jogo contraditório nas interpretações sobre a autora colocadas em cena pelo/ no discurso jornalístico. Examinamos os processos de designações e seus funcionamentos ideológicos em manchetes de jornais, os quais operam processos de identificação para a escritora e seu livro. Analisamos, também, o funcionamento do nome próprio e da designação "escritora negra". As análises permitem dizer que Quarto de Despejo passa a funcionar como referência básica no imaginário constitutivo do Brasil, pois inaugura filiações de memória que permitem significar as sujeitas mulheres negras em relação com outros lugares de enunciação. 
Palavras-chave: Carolina Maria de Jesus. Quarto de Despejo. Designações. Manchetes de jornal. Nome próprio.

\section{RÉSUMÉ}

Cet article cherche à comprendre, à partir de la lumière théorique de l'Analyse du Discours, les gestes d'interprétation pour Carolina Maria de Jésus dans la presse en 1960, lorsque I'auteur a lancé Quarto de Despejo: diário de uma favelada. Femme noire, mère, écrivain, résidente de la Favela du Canindé et recycleuse, Carolina Maria de Jesus a eu sa première œuvre traduite en 14 langues et vendue dans plus de 40 pays. Au Brésil, au moment du lancement de Quarto de Despejo, Carolina était désignée par la presse nationale tantôt comme "a favelada", tantôt comme "écrivaine-favelada", ce qui donne à voir le jeu contradictoire dans les interprétations sur l'auteur mises en scène par/dans le discours journalistique. Nous avons examiné les processus de désignations et leurs fonctionnements idéologiques dans les manchettes des journaux, qui opèrent des processus d'identification pour l'écrivain et son livre. Nous analysons également le fonctionnement du nom propre et de la dénomination "écrivain noir". Les analyses permettent de dire que Quarto de Despejo devient une référence de base dans l'imaginaire constitutif du Brésil, car il inaugure des filiations de mémoire qui permettent de signifier les femmes noires par rapport à d'autres lieux d'énonciation.

Mots-clés: Carolina Maria de Jesus. Quarto de Despejo. Désignations. Titres de journaux. Prénom.

\section{INTRODUÇÃO}

Como a mídia informativa interpreta Carolina Maria de Jesus e sua primeira obra no ano de publicação de Quarto de Despejo: diário de uma favelada? O que o funcionamento discursivo dos processos de designação pode nos mostrar sobre os sentidos produzidos para Carolina e seu livro, quando postos em circulação pela mídia informativa? Consideramos que a imprensa jornalística constitui um discurso sobre ${ }^{1}$ Carolina cujos sentidos se delineiam no jogo contraditório entre posições de sujeito antagônicas. Esse discurso sobre é estabelecido por meio de gestos de interpretação cujo direcionamento ideológico aponta para

1 Foi Eni Orlandi (2008) quem primeiro problematizou o funcionamento do discurso sobre. Em seu livro Terra à vista. Discurso do confronto: velho e novo mundo, ela o considera como uma das formas de institucionalização dos sentidos, onde trabalha o conceito de polifonia. Assim, consideramos que o discurso sobre organiza e disciplina a memória, com consequências para os modos de significar Carolina e Quarto de Despejo. 
processos que designam Carolina a partir de um espaço específico da cidade: a favela.

Embasadas no aporte teórico da Análise de Discurso, na esteira dos trabalhos de Michel Pêcheux e Eni Orlandi, intenta-se produzir uma compreensão dos gestos de interpretação da imprensa depreendidos do exame das designações formuladas em notícias, sobretudo em manchetes de jornais da época. Assim, objetivamos investigar como os modos de designação para autora e obra retomam, mantém ou deslocam sentidos, constituindo processos de subjetivação/identificação que constituem o sujeito Carolina em relação ao espaço da favela e às disputas que se ocupam de afirmar identidades legitimadas socialmente. Interessa-nos, igualmente, compreender o funcionamento de efeitos de exclusão e silenciamento tendo em vista os processos de produção discursiva da identidade de sujeitas mulheres negras ${ }^{2}$, socialmente discriminados e significados pelo discurso da escravidão e do colonialismo.

Compreendemos que a produção de sentidos que significam Carolina como favelada é hegemônica, dada a direção interpretativa ideológica, na referência às condições de produção do material analisado. No entanto, embora sejam dominantes, os sentidos não podem ser considerados homogêneos, pois estão submetidos à sobreposição de espaços de memória múltiplos e conflitantes que produzem as identidades de mulheres negras e, também, dizem da elaboração simbólica do espaço urbano. Há uma heterogeneidade que se dá pelas brechas, pela quebra do ritual ideológico, e que este trabalho se esforça por evidenciar.

Neste artigo, o funcionamento das designações no discurso jornalístico ${ }^{3}$ é discutido a partir de um corpus analítico foi composto por um conjunto de manchetes de jornais publicadas em 1960, ano de lançamento de Quarto de Despejo. Esse material, pesquisado no arquivo da Biblioteca Nacional Digital, foi recortado de jornais em circulação à época. Priorizamos os periódicos do Estado de São Paulo, haja vista que o lançamento da obra se deu nesta capital. O corpus, que evidencia as designações formuladas para a autora, é constituído de cinco manchetes: (I) "Lançamento do diário da favelada", (II) "Livro da favelada causa complicações na edilidade", (III) "Homenagem na

2 Optamos pelo uso de "sujeitas mulheres negras" em referência ao trabalho de Cestari (2015), que nos coloca a pensar as mulheres negras como sujeitas de dizer no campo da luta antissexista e antirracista.

3 Compreendemos que o discurso jornalístico ocupa lugar de destaque na sociedade. Seu funcionamento opera no movimento entre informar e construir a realidade enquanto efeito da credibilidade dos jornais e dos processos de produção discursiva da referência. Ele "apresenta-se textualmente pela predominância da narração em terceira pessoa e pelo apagamento das marcas do sujeito da enunciação no enunciado." (BACCEGA; AZEVEDO, 2007, p. 99). 
campanha da Associação Cristã Feminina à Carolina Maria de Jesus", (IV) "Líderes do Movimento Cultural do Negro homenageiam a escritora Maria Carolina", (V) "São Paulo lança escritora negra: Carolina Maria".

As manchetes - entendidas aqui como uma materialidade discursiva que possui modo próprio de formulação, constituição e circulação (ORLANDI, 2020) - conduzem o olhar do leitor, direcionam sua interpretação do início ao fim do texto. Depreende-se que o leitor é convocado para um dado lugar de interpretação e assume um dado sentido. Entretanto, o trabalho da interpretação não se limita a uma formulação interpretativa única, não estaciona em uma só direção possível. O analista de discurso interroga possíveis caminhos, uma vez que ele não interpreta, mas "trabalha (n)os limites da interpretação" (ORLANDI, 2020, p. 59); ele mostra, por meio de seus procedimentos, os gestos de interpretação que direcionam os sentidos. Consideramos, assim, que o movimento do gesto de interpretação, face à abertura dos processos de significação (ORLANDI, 2020), permite-nos trabalhar as condições de produção dos objetos simbólicos, o como os sentidos são produzidos e significados.

\section{O FUNCIONAMENTO PARADOXAL DA IDEOLOGIA NAS DESIGNAÇÕES}

Segundo Zoppi-Fontana (2003), os processos de designação se caracterizam por nomear através de categorias já estabilizadas discursivamente. Entretanto, embora apontem para a produção de um sentido determinado, implicam processos instáveis, dado que são "produzidas pelo cruzamento de diferentes posições de sujeito", a partir das quais instala-se um sentido. Para a autora, os processos de designação trabalham

indícios dos pontos de estabilização das relações de referência no interdiscurso, sendo reconfiguradas no acontecimento enunciativo a partir do embate das condições de produção sobre a língua (enquanto estrutura formal capaz de equívoco na história) e sobre a memória (enquanto corpo sócio-histórico de traços discursivos que se constituem em espaço de estruturação, de regularização de sentidos) (ZOPPI-FONTANA, 2003, p. 253).

O modo como as designações são empregadas constrói um percurso de leitura e estabelece um efeito-leitor ${ }^{4}$ complacente com as

4 Definimos efeito-leitor consoante Orlandi (2007, p. 75), como aquilo que representa a exterioridade constitutiva do autor. Segundo a autora, "o autor se produz pela possibilidade de um gesto de interpretação que lhe corresponde e que vem de fora". Isso quer dizer que a posição-autor deriva da constituição de um lugar de interpretação que 
formações ideológicas inscritas no texto, em decorrência das projeções imaginárias que constituem as condições de produção. Sedimentamse e naturalizam-se efeitos de sentido que identificam Carolina na relação com a favela, constituindo sua identidade como feixe instável de processos de identificação.

A manchete escolhida para iniciar nossas análises (Fig. 1) foi veiculada no periódico Correio Paulistano, publicado em São Paulo, no dia 18 de agosto de 1960, um dia antes do lançamento de Quarto de Despejo. O título "Lançamento do Diário da Favelada" precede a notícia que convida o público a prestigiar "o mais sensacional lançamento de autógrafos já realizado". Trata-se "[d]o diário da favelada Carolina Maria de Jesus". Além do lançamento, noticia-se também a presença de Batista Ramón, ministro do trabalho na época, que "aceitou o convite para ser padrinho da escritora-favelada". Por fim, a notícia relata que a livraria Francisco Alves está "especialmente decorada com vitrina, faixas com frases do diário" e, mais do que isso, "com todo o material alusivo a este lançamento que vai revolucionar o mercado editorial do país".

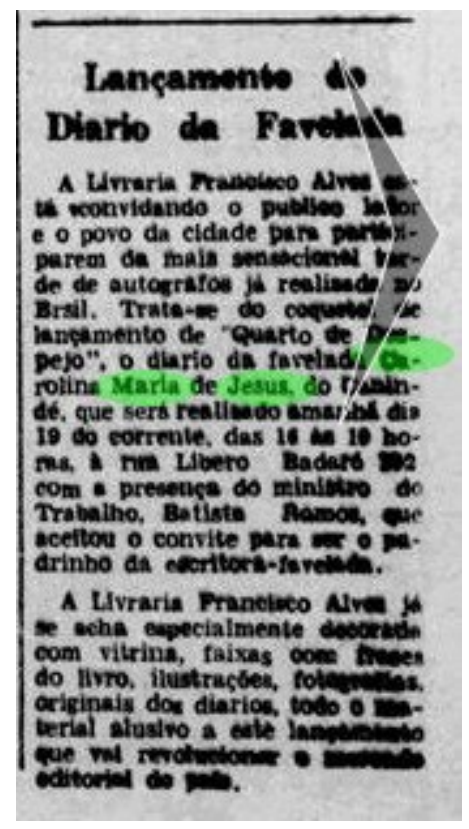

Figura 1: Jornal Correio Paulistano, São Paulo, 18 de agosto de 1960.

Fonte: Correio Paulistano, São Paulo, 18 de agosto de 1960.

se define pela relação com o Outro (o interdiscurso) e o outro (o interlocutor). O efeito-leitor representa, portanto, essa relação de exterioridade simbólica (e não empírica) que compreende o Outro e o outro. 
A formulação evidenciada na manchete "Lançamento do diário da favelada" é recorrente em manchetes de periódicos da época e deixa entrever processos de significação cuja constituição tem relação com determinada região do espaço urbano, a favela. Nessa formulação, o nome "escritora" é elidido e aparece apenas ao final da notícia, formulado com hífen: "escritora-favelada". Verifica-se que a marca da designação "favelada", repetida duas vezes no corpo da matéria, aparece antes mesmo do nome da autora, produzindo efeitos sobre ele. Podemos perceber isso em: "trata-se do coquetel de lançamento de 'Quarto de Despejo', o diário da favelada Carolina Maria de Jesus, do Canindé". Aqui a relativa explicativa acrescenta uma qualidade acessória ao antecedente, marcando-o pela determinação de um lugar, "do Canindé". Os sentidos de "favelada", no entanto, são dados antes e em outro lugar, independentemente. Eles têm relação com uma história política dividida que estabelece os espaços das cidades a partir de relações de classe e raça dessimétricas.

Observa-se a produção da evidência: "todos sabem" o que seja uma favelada. Entretanto, a partir Pêcheux entende-se que o sentido de "favelada" não existe em si mesmo (PÊCHEUX, 1995), mas é determinado de acordo com as posições ideológicas em jogo, sustentadas pelos jornais que a formulam, em uma dada condição de produção: "as palavras, expressões, proposições etc., mudam de sentido segundo as posições sustentadas por aqueles que as empregam, o que quer dizer que elas adquirem seu sentido em referência a essas posições, isto é, em referência as posições ideológicas" (PÊCHEUX, 1995, p. 160). Acrescente-se, ainda, que essas ideologias são práticas da luta classes.

Assim, os sentidos de "favelada" não se encontram colados ao nome, mas são constituídos por processos ideológicos que em parte significam a favela, em 1960, a partir de vestígios de uma política higienista de organização das cidades brasileiras difundida no Brasil desde o final do Séc. XIX e início do XX, a qual determina para os corpos considerados "inadequados", corpos pobres e sobretudo negros, espaços de segregação e divisão que se materializam na linguagem. A ideologia higienista encontra-se no cerne de formação das favelas e está atrelada à intervenção na ordem das cidades para impor disciplina das condições de vida por meio da higiene pública. Em nome do progresso, ela disciplina espaços e corpos, tece "para a cidade um mapa esquadrinhado por relações sociais desiguais, nas quais impera o sexismo e o racismo" (BOCCHI, 2018, p. 223). 
Assim, a ideologia fornece o sentido do que seja uma "favelada", em um processo que funciona produzindo uma evidência sobre esse nome. Com Pêcheux, compreende-se que os sentidos para a designação "favelada" são construídos historicamente tendo em vista redes de memória em que os corpos das mulheres negras são significados pelo discurso da escravidão e do colonialismo, considerando-se que a luta ideológica se estabelece também no campo da linguagem. Esse funcionamento, colocado em relevo pela mídia informativa, entendida aqui como aparelho ideológico que enceta uma prática ideológica, serve a determinados interesses de classe.

Entretanto, a última designação que estampa essa notícia indicia o funcionamento da "designação dividida", conforme Zoppi-Fontana (2003). Trata-se da formulação "escritora-favelada", na qual a palavra "escritora" tem seus sentidos constituídos na relação com "favelada", que funciona aí como modo de adjetivação. Ao fazer o uso do hífen, a designação "escritora-favelada" torna-se uma palavra composta, capaz de determinar o sentido de "escritora" e operar na desestabilização da evidência do nome "favelada", cujos sentidos são colocados em cheque. A ocorrência dessa designação opera como efeito de clivagem, quebrando o efeito de evidência do nome favelada ao inscrever uma posição de sujeito antagônica, pela operação de determinação que suspende a estabilização de sentidos para favelada e para a favela, que passa a ser um lugar de existência para sujeitas escritoras negras.

Assim ao consideramos o caráter não homogêneo da memória discursiva, que se apresenta como espaço móvel de divisões, disjunções, deslocamentos, conflitos e regularização, conforme Pêcheux (1983), instala-se a contradição na produção de discursos sobre Carolina e Quarto de Despejo. Segundo Zoppi-Fontana (2003, p. 252), as designações divididas fornecem um observatório privilegiado para a análise dos efeitos da contradição entre posições de sujeito; elas "sinalizam os pontos de ruptura/desestabilização referencial, nos quais a própria identidade do sujeito e do discurso (que nomeia/nomeado) oscila, suspendendo os efeitos de evidência do sujeito e do sentido."

\section{O DIÁRIO DA FAVELADA: EFEITOS DE UMA PARÁFRASE}

Ainda com referência à manchete anterior, é possível compreender o gesto de interpretação que reescreve o título da obra Quarto de Despejo: diário de uma favelada, estabelecendo um discurso sobre. Ao formular a manchete "Lançamento de Diário da Favelada", apaga-se o 
título principal do livro, Quarto de Despejo, ao mesmo tempo que se enfatiza o subtítulo. Entretanto, há um deslocamento no subtítulo original, "Diário de uma favelada", que assume nessa manchete a formulação "Diário da Favelada", que passa a atuar como um atributo para Carolina. Essa passagem do "de uma" para o "da" produz um efeito ideológico de universalização em que emerge uma generalização acerca de Carolina. Essa universalidade corrobora ao funcionamento do "todo mundo sabe", efeito da ideologia, como postula Pêcheux; ela é um efeito imaginário necessário à reprodução das relações de produção.

Considerado uma escrita de si, o diário constitui traços de memória e de constituição subjetiva na composição e historicização daquele que se subjetiva ao escrevê-lo. Em uma perspectiva discursiva, compreendemos o diário como um testemunho, consoante Bocchi (2017), que enseja processos de identificação e individuação, um modo narrar a experiência do sujeito em dizeres permeados por equívocos; a escrita testemunhal carrega marcas, revela cicatrizes dos sujeitos que participam dessa experiência. Para Schons e Munhoz (2015), escrever um diário é "falar de si e assumir a incompletude do sujeito e do sentido"; escrever implica a existência de um autor que se entrega a gestos de interpretação ao inscrever-se como origem dos sentidos.

Enquanto lugar de interpretação, a escrita constitui um espaço simbólico que articula língua e história. Ela participa de processos de subjetivação e, também, individuação, posto que por meio dela o sujeito se individualiza em relação a discursos e práticas que o submetem. Esses processos se materializam no título e subtítulo do diário de Carolina; enquanto o primeiro organiza sentidos para um lugar específico, a favela, o segundo localiza uma experiência singular neste espaço, "de uma favelada". Nessa formulação, há uma marca de singularidade, de um sujeito que se individualiza por meio da escrita. Assim, ao reescrever o subtítulo como "diário da favelada", a manchete apaga uma marca de singularidade, produz um processo de des-individuação ${ }^{5}$.

Para Orlandi (2010, p. 4), a constituição do sujeito se dá por meio de dois movimentos inseparáveis, no primeiro "temos a interpelação do indivíduo em sujeito, pela ideologia, no simbólico, constituindo a formasujeito-histórica", já no segundo, "com esta forma-sujeito histórica já constituída" dá-se então o que a autora considera como processo de individuação do sujeito. A respeito disso, Orlandi coloca que essa "noção de sujeito individuado não é psicológica, mas política, ou seja, a relação

5 Sobre o processo de des-individuação, ver Bocchi (2019). 
indivíduo-sociedade é uma relação política". Um sujeito individuado, pensado em sua relação política e entendido como um corpo político, corresponde ao sentimento de ser Um no todo da sociedade.

\section{APROPRIAÇÃO DISCURSIVA E INSTRUMENTALIZAÇÃO DA FALA NO DISCURSO DO COLONIZADOR}

A manchete "Livro da favelada provoca complicações na edilidade" (Fig. 2), veiculada no periódico Diário da Noite, intitula a matéria em que o então vereador Silva Ribeiro saúda "o aparecimento de Quarto de Despejo, da favelada Carolina Maria de Jesus", como um "símbolo da opinião pública a respeito dos políticos" e também como um livro de "denúncia" ao falar sobre a "situação de miséria reinante nas favelas". Ao lê-la entende-se que o "livro da favelada" provocou "complicações" na câmara dos vereadores, entendida aqui no termo "edilidade". Além de utilizar a designação "favelada", que retoma a evidência de sentido do nome, o emprego das palavras "provocar" e "complicações" estabelece uma relação lógica destes para com o "livro da favelada". Entretanto, quais complicações seriam essas?

\section{LIYRO DA FAVELADA PROVOCA COMPLICAÇOEES NA EDILIDADE \\ O vereador silva Ribeiro oecu- pois a tribuna, na sestiso de on. tem da Camara Municipal para sacidar o aparecimento do firro "Quarto de Despejo" da favela. da Carolina Maria de Jesus, como um simbolo da opiniaio pur. blica a respeito dos poiticos e uma denuncla da stuacto de mis seria reinante nas favelas. Con- cluia o seu discurso lendo um trecho do livro $\mathrm{cm}$ que o ex-ve. \\ reador Cantidio Sampato é men ctonado, como antigo vistante da Favela do Canindé \\ A referencla no st Silra Rl. beiro, do PL pareced intencionsl ao ir Helio Menidonca do PSP. amtigo pessoal do ir Cantidio Satnpoto. que em sessio anteriot eneaminhara tequerimento de corstatulacolet com a livraria que editou o livro}

Figura 2: Diário da Noite, 1960, p. 3.

Fonte: Diário da Noite, 1960, p. 3.

A matéria em si não apresenta tais "complicações", cujo sentido é construído interdiscursivamente, pela filiação a uma rede de memória. O funcionamento da manchete condiciona o leitor a crer nessas complicações provocadas pelo livro, embora não pontue tais adversidades que Quarto de Despejo possa ter ocasionado na câmara dos vereadores. Entretanto, ao formular, no corpo da matéria, o livro como "símbolo da opinião pública a respeito dos políticos e uma denúncia 
da situação de miséria reinante na favela", a notícia constitui para ele sentidos subversivos à ordem da edilidade.

A matéria ainda diz que o vereador Silva Ribeiro terminou seu discurso fazendo a leitura de um trecho da obra em que um ex-vereador Cantidio Sampaio é mencionado como "visitante" da favela. Dispensável dizer que "visitante" é, justamente, um não-morador, ou seja, aquele que não pertence ao grupo dos favelados. Aparentemente essa leitura foi "intencional ao Sr Helio Mendonça, do PSP, amigo pessoal do Sr. Cantidio Sampaio". Assim, compreende-se que o vereador Silva Ribeiro usa o livro de Carolina em ataque aos adversários políticos do PSP, Partido Social Progressista, que não por acaso foi fundado por Ademar de Barros $^{6}$ em junho de 1946.

Esse processo discursivo permite descortinar as práticas políticas em vigência, as quais se apropriam da fala dos pobres, suas mazelas e dores, em suas disputas políticas. Tal prática instrumentaliza o livro de Carolina, usando-o para "provocar complicações" para os adversários políticos. O "aparecimento" do livro é, portanto, saudado não por materializar o testemunho do sofrimento de Carolina e de sua família ou por expor a face vil e cruel de uma sociedade desigual e racista como a brasileira, mas porque serve de munição à disputa política. Há uma apropriação discursiva, nos termos de Paveau (2017), que instrumentaliza o discurso de "locutores vulneráveis".

Como disse Spivak (2010), a fala do subalterno é recoberta pela do Sujeito soberano. Ainda, "[s]e o discurso do subalterno é obliterado, a mulher subalterna encontra-se em uma posição ainda mais periférica pelos problemas subjacentes às questões de gênero. [...] O subalterno não tem história e não pode falar, o sujeito subalterno feminino está ainda mais profundamente na obscuridade" (SPIVAK, 2010, p. 14-15).

A respeito das problemáticas que envolvem as mulheres negras, Lélia Gonzalez considera que ser negra e mulher no Brasil "é ser objeto de uma tripla discriminação, uma vez que os estereótipos gerados pelo racismo e pelo sexismo a colocam no mais alto nível de opressão" (GONZALEZ, 2020, p. 58). Ao impor um lugar inferior dentro de sua hierarquia (sustentada por condições biológicas de sexo e raça) à mulher negra, tais funcionamentos suprimem a humanidade precisamente porque negam o direito de existência enquanto sujeitas não apenas de seus próprios discursos, mas de suas próprias histórias (GONZALEZ, 6 A favela do Canindé, onde residia Carolina, era situada às margens do Rio Tietê e foi construída em 1948 por Adhemar de Barros. Vera Eunice, filha de Carolina, afirma que sua mãe contava que Ademar de Barros mandou recolher das ruas as pessoas pobres, por ocasião da visita de um diplomata americano. Sobre essa questão, consultar Buranelli (2021). 
2020, p. 141). Ao interrogar o racismo estrutural e desigualdade racial, Gonzalez denuncia a dominação branca e europeia que denega as raízes africanas e, também, as origens indígenas e latinas. Nessa direção, Lélia considera "impossível combater o racismo se as pessoas brancas não reconhecerem nossa condição colonial" (RODRIGUES, 2020, s/n).

Difícil tarefa, já que valorizar a origem europeia é parte do processo de denegar a latinidade e de sustentar o racismo contra negros e indígenas, a serem estigmatizados como "Os outros", "os bárbaros" ou, no vocabulário contemporâneo, "os bandidos" e até "os invasores", mesmo que o termo seja usado em referência ao povo nativo. Há aqui um jogo de inversões do qual depende a opressão colonial: para afirmar-se no poder, os colonizadores precisam dominar não apenas os corpos, mas sobretudo o imaginário de cada povo dominado, atribuindo valor simbólico ao europeu branco, naturalizado como quem tem o direito de ocupar o lugar de dominação, e destituindo de valor simbólico todo não branco que fica destinado à subalternidade. Assim se constitui um duplo mecanismo, a afirmação da superioridade do colonizador e a alienação do colonizado (RODRIGUES, 2020, [n.p.]).

"Os outros", "Os bárbaros", "Os bandidos", "os invasores", "Os favelados" que "provocam complicações". Designações carregadas de sentidos constituídos a partir de redes de filiação histórica que organizam o dizível, dando lugar a processos de identificação segundo os quais o sujeito encontra as evidências que permitem seu dizer. A memória discursiva é entendida aqui como "o espaço dos efeitos de sentidos que constituem para o sujeito sua realidade, enquanto representação imaginária (e necessária) da sua relação com o real histórico, no qual ele está inserido" (ZOOPI-FONTANA e CESTARI, 2014, p. 168).

Nota-se como os jornais (em aliança com outros Aparelhos de Estado, como é o caso da Edilidade) atuam na constituição de um imaginário a partir da posição do colonizador, produzindo para Carolina, mulher negra, sentidos permeados pelo racismo estrutural e sistemático. Desse modo, as manchetes de jornais são capazes de manusear discursos que perfazem o poder do colonizador a fim de manter o colonizado em sua posição de subalternidade, através da atribuição de "valor simbólico ao europeu branco, naturalizado como quem tem o direito de ocupar o 
lugar da dominação, e destituindo de valor simbólico todo não branco que fica destinado a subalternidade".

\section{DE QUE MULHERES ESTAMOS FALANDO?}

A manchete abaixo (Fig. 3) foi veiculada no Diário da Noite, em São Paulo, no ano de 1960, e nos apresenta como título: "Homenagem na campanha da Associação Cristã Feminina à escritora favelada". Como matéria, temos que tal associação de mulheres homenageou Carolina Maria de Jesus em sua primeira reunião social, de acordo com seu plano de Campanha Financeira. O objetivo da reunião foi "angariar fundos para atender às necessidades da organização acefista em S. Paulo, entidade essa de âmbito mundial, voltada para obras de elevado cunho sócioassistencial de ajuda à mulher". Na ocasião, a presidente da campanha, Maria Lício Rizzo, "saudou a escritora favelada", que autografou o "seu Quarto de Despejo". Destaca-se o emprego do pronome "seu", que estabelece uma diferença entre o Quarto de Carolina (dela) e o espaço das demais mulheres da associação.

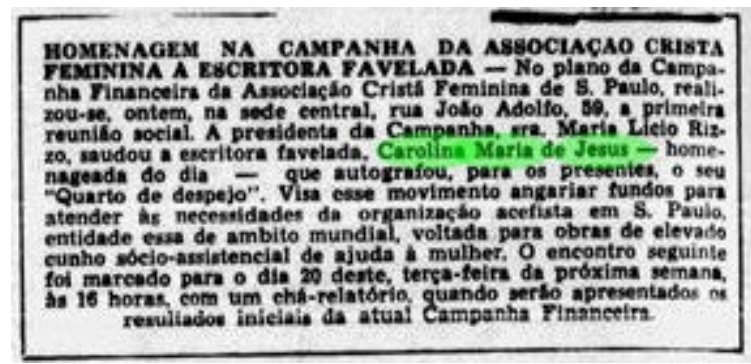

Figura 3: Diário da Noite, 1960.

Fonte: Diário da Noite, 1960, [n.p.].

Assim, o sentido de "mulheres" mostra-se equívoco, pois sua significação, articulada ao emprego do pronome possessivo ("seu Quarto de Despejo"), organiza uma diferença significante entre aquelas que ajudam, assistem, e aquelas que são assistidas pela associação. Nessas formulações, os sentidos para "mulheres" se estabelecem a partir da sinonímia mulheres = mulheres brancas de classe média, sustentada pela eficácia da ideologia, e não um lugar de identificação e representação política de todas as mulheres. Há uma disputa de sentidos em torno de "mulheres" que se sustenta em uma relação de poder dessimétrica e desigual, interseccionada às questões raciais.

Esse processo discursivo dá a ver sentidos de benevolência atribuídos à mulher branca, associados à ideia de bondade e generosidade 
de práticas assistencialistas que funcionam reproduzindo estruturas racistas. Nesse imbricamento, há também a caridade da mulher cristã, que atua como benevolente por meio de sua religião. Entretanto, essa mulher branca, cristã e bondosa representa apenas uma parte das mulheres. Embora se autodesigne como uma associação "feminina" e não feminista, temos um discurso assistencialista pautado pelo assistencialismo, o qual se sustenta em um pré-construído: uma suposta superioridade das mulheres brancas em relação a outras mulheres, "assistidas" pela associação. Essa questão parece tangenciar a ideia dos movimentos feministas alocados nas primeiras ondas ${ }^{7}$, que durante muito tempo apresentaram reinvindicações de mulheres brancas, excluindo demandas e especificidades das mulheres negras, indígenas e periféricas.

Nessa direção, bell hooks, feminista negra estadunidense, nos convida a refletir sobre a supremacia da mulher branca nos movimentos feministas e sobre como é possível identificar, em seus discursos, funcionamentos que desconsideram pautas sobre raça e classe. A autora coloca:

As mulheres brancas que dominam o discurso feminista - as quais, na maior parte, fazem e formulam a teoria feminista - têm pouca ou nenhuma compreensão da supremacia branca como estratégia, do impacto psicológico da classe, de sua condição política dentro de um Estado racista, sexista e capitalista (hooks, 2015, p. 196).

hooks ainda pontua que "o racismo abunda nos textos de feministas brancas, reforçando a supremacia branca e negando a possibilidade de que as mulheres se conectem politicamente, cruzando fronteiras étnicas e raciais" (2015, p. 196). Por essa perspectiva, compreendemos que a manchete anterior, ao reforçar um pré-construído da benevolência da mulher branca, tangencia o pensamento de hooks quando nos mostra a supremacia branca que denega e silencia pautas de mulheres negras.

Por isso, evocamos Sueli Carneiro (2011, s/n), que ao questionar "de que mulheres estamos falando?" provoca uma reflexão sobre quais feminismos e mulheres são representados diante das pautas dos movimentos feministas. Por essa perspectiva, fomenta o debate sobre como as mulheres negras, durante as primeiras ondas dos movimentos

7 Consideramos feminismo como um termo que engloba de modo geral seu processo histórico. Por isso o dividimos em três grandes movimentos: a primeira onda é marcada pela luta sufragista, isto é, a reivindicação ao direito do voto feminino no país; a segunda teve como de pano de fundo a efervescência política e as pautas se estendiam para além dos votos, como por exemplos questões relacionadas ao corpo, à sexualidade e à violência sexual e, por fim, a terceira onda é caracterizada por discussões sobre gênero, raça e classe, e é quando o movimento expõe sua face excludente dado que apenas uma parte das mulheres se sentia representada. É nesse momento também que pautas relacionadas ao gênero se tornam uma ferramenta importante para a luta. (BURANELLI, 2021). 
feministas, tiveram suas histórias narradas pela posição privilegiada da mulher branca, ou seja, suas histórias foram significadas por outras vozes, o que consequentemente produz silenciamento, opressão e ausência de representatividade. Carneiro coloca em destaque a problemática da interseccionalidade que atravessa as opressões e violências vivenciadas pelas mulheres negras; a partir dela, compreende-se que questões que interseccionam sexismo, classe e raça são imprescindíveis para compreender os movimentos feministas negros e a constituição da sujeita mulher negra. A respeito disso, essa intelectual propõe para os feminismos negros uma definição:

Construído no contexto de sociedades multirraciais, pluriculturais e racistas - como são as sociedades latinoamericanas - tem como principal eixo articulador o racismo e seu impacto sobre as relações de gênero, uma vez que ele determina a própria hierarquia de gênero em nossas sociedades. (CARNEIRO, 2011, [n.p.])

Ao questionar "de que mulheres estamos falando?" e considerar que é preciso "enegrecer o feminismo brasileiro", Carneiro afirma a importância de introduzir e instituir pautas que privilegiem a questão racial, de gênero, da violência contra a mulher negra como reguladores da luta feminista negra. A autora ainda coloca que destacar as contradições como efeito da articulação entre raça, classe e gênero, sustentadas por mulheres negras e o movimento negro, possibilita "as reivindicações das mulheres, tornando-as assim mais representativas do conjunto das mulheres brasileiras, e, por outro lado, promovendo a feminização das propostas e reivindicações do movimento negro (CARNEIRO, 2011, [n.p.]).

Assim, compreendemos que os marcadores de raça, classe e gênero se cruzam de modo que é impensável considerá-los de maneira isolada. Refletir sobre Carolina é reconhecer as intersecções que acometem as significações constitutivas para a autora, bem como as múltiplas opressões que se cruzam, na compreensão de sua real condição de existência, enquanto mulher, negra, mãe e escritora que residia na periferia.

\section{O NOME PRÓPRIO: EFEITOS DE UMA INVERSÃO}

A matéria abaixo (fig. 4), veiculada no jornal Diário da Noite, de São Paulo, tem como manchete "Líderes Do Movimento Cultural do Negro Homenageiam a Escritora Maria Carolina". Há o emprego 
de "escritora", porém precedido de um "erro" no nome de Carolina, uma inversão no nome próprio da autora, nomeada "Maria Carolina". O funcionamento dessa manchete dá a ver o equívoco no modo de identificação de Carolina; ela só pode ocupar um espaço como escritora transmutada em Maria Carolina. Há, aqui, uma dupla negação: negase Carolina como escritora e, no mesmo gesto, nega-se a ela tornar-se sujeito por meio da identificação com um nome próprio.

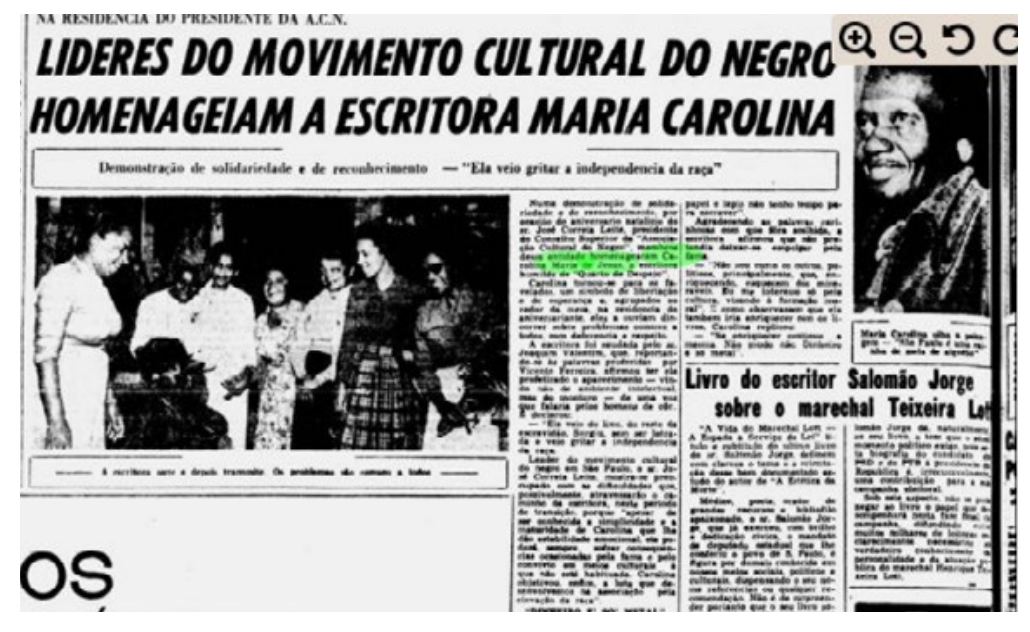

Figura 4: Diário da Noite, 1960.

Fonte: Diário da Noite, 1960, p. 12

Segundo Garcia e Sousa (2015, p. 52), nosso país ainda reserva aos negros posições subalternas e desfavorecidas. Ao analisarem a história do negro e a posição por ele ocupada na história do Brasil, as autoras relatam que se observam dizeres que "colocam o negro como coisa". Cabe ressaltar que há, ainda, diferenças na maneira como esses efeitos incidem sobre homens e mulheres negras, segundo Giacomini (1988). A história do negro, ao ser marcada por preconceito, sobretudo da mulher negra relegada à condição sexual com raízes na escravidão, como salienta Giacomini, é ainda presente. Contudo, "embora funcione na sociedade um lugar ao negro à margem (terrível e degradante), este resiste e busca ocupar espaços além dos limites das favelas e dizer-se sujeito de direitos" (GARCIA e SOUSA, 2015, p. 54).

É nesse espaço de (re)existência que Carolina escreve, também para ocupar com sua obra lugares que não o subalterno, questionando a condição social a que ela é submetida pelo sistema. Enquanto mulher 
negra, pobre e moradora do Canindé há hesitação, na mídia informativa da época, de designá-la "escritora". É assim que a determinação de sentidos para seu nome, ora por meio da designação "a favelada", ora por inversão de seu nome, adverte sentidos velados pelo preconceito, pela hostilidade e pela segregação.

Nesse percurso, considero o que pontua Lélia Gonzales ao dizer que "negro tem que ter nome e sobrenome, senão os brancos arranjam um apelido... ao gosto deles" (BAIRROS, 2000, p. 2). Isso implica que a inversão do nome próprio produz a negação dos direitos do sujeito e, ainda, de sua existência. Bocchi, com base em Butler, afirma que "a existência social do corpo só é possível por meio do processo de interpelação simbólico: receber um nome é um artifício linguístico que permite a constituição do sujeito da linguagem". Se o sujeito da linguagem se constitui ao receber um nome enquanto um endereçamento $(\mathrm{BOCCHI}$, 2017a), na manchete em questão, a inversão desse nome próprio pretere a autora a um lugar de negação, de não aceitação dessa mulher negra.

Entretanto, é importante notar que, no caso do nome próprio, os mecanismos de identificação funcionam de modo específico. O nome próprio é aquele que participa da produção de identificação para o sujeito a partir de uma nomeação particular, que lhe é dada ao nascer; é por meio dele que se constitui e legitima alguém enquanto sujeito. A respeito dessa consideração, Mariani nos coloca:

É a partir desse nome legalmente validado que podemos ser designados socialmente, mesmo que à nossa revelia. Esse funcionamento linguístico e social mostra tanto o aspecto convencional do nome próprio quanto implica seu caráter referencial, produzindo um efeito de identidade por sua repetição. O nome próprio funciona como uma referência para o sujeito, uma vez que o sujeito é designado e se designa a partir desse nome que lhe é dado ao nascer (MARIANI, 2014, p. 133-134).

Conforme Guimarães (2003, p. 54), "um nome, ao designar, funciona como elemento das relações sociais que ajuda a construir e das quais passa a fazer parte. Dar nome a algo [...] é dar-lhe existência histórica". Dito isso, perguntamos: o que se diz ao dizer errado o nome de alguém? O que se nega nessa nomeação "defeituosa"? Considera-se, assim, que a inversão do nome próprio formulada na manchete nega à Carolina não apenas sua existência enquanto escritora, mas também seu estatuto de sujeito de direito, ao não permitir que ela faça parte das relações sociais, da existência histórica como pontua Guimarães (2003). 


\section{A "ESCRITORA NEGRA" E A FALHA NO RITUAL IDEOLÓGICO}

O recorte abaixo (fig. 5) foi retirado do Jornal do Brasil, veiculado no Rio de Janeiro, no ano de lançamento de Quarto de Despejo. Embora os outros recortes selecionados e analisados sejam de São Paulo, convoco essa manchete pois ela coloca em circulação outros sentidos, mobilizados através da falha do ritual ideológico. A manchete "São Paulo lança uma escritora negra: Carolina Maria" revela não mais a repetição, mas um novo sentido possível por meio do emprego da designação "escritora negra". Infiro ainda que neste recorte podemos perceber que o sentido dominante não é homogêneo dado que pela falha ideológica a heterogeneidade do sentido atua. Pelas brechas é que se pode constatar que há diferentes de significação, e que a produção de sentidos sobre Carolina não uniforme.

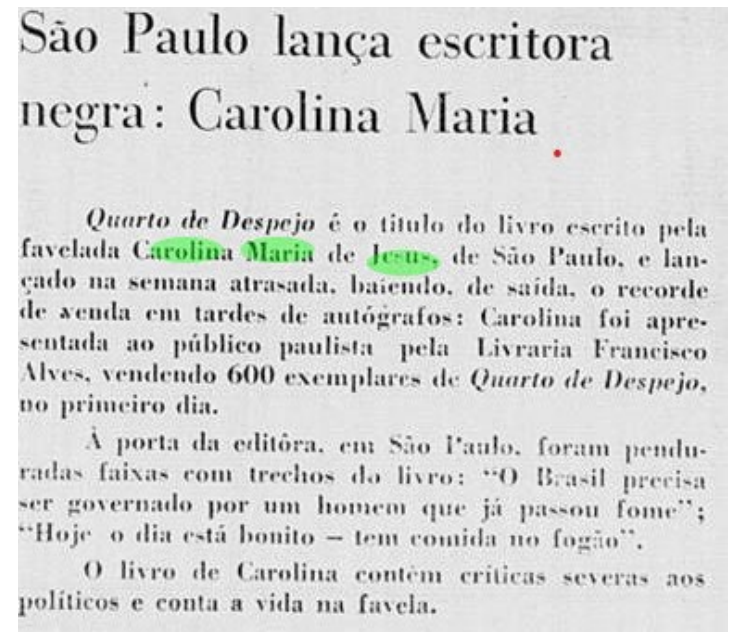

Figura 5: Jornal do Brasil, 1960.

Fonte: Jornal do Brasil, 1960, [n.p.].

Há, aqui, um processo polissêmico, dado que temos um deslocamento no sentido da designação "favelada" encontrada com certa recorrência nas manchetes, ao contrário dos processos parafrásticos, em que há algo da ordem da repetição, neste recorte vemos a polissemia atuar. A manchete em questão (fig. 5) não nos traz os processos de repetição de um sentido que se mantém, ela atesta a ruptura, ele atesta a ruptura, a descontinuidade da designação "favelada" para "escritora negra". Temos, então, um sentido "diferente: nas mesmas condições de produção imediatas (locutores e situação) há no entanto um 
deslocamento, um deslizamento de sentido (polissemia)" (ORLANDI, 1998, p. 15).

Essa atuação da polissemia na ruptura dos sentidos, em que sinaliza a possibilidade de uma nova designação que até então não aparecia, ela atesta, também, o lugar da ideologia. Isto é, o "escritora negra", como na manchete, manifesta uma quebra de sentido e demonstra, ainda, também a potência de Quarto de Despejo como um acontecimento que se faz pelas brechas, pela quebra do ritual ideológico.

Nesse sentido, esse recorte dá a ver que a ideologia é um ritual com falhas, conforme Pêcheux (1995, p. 277):

Apreender até seu limite máximo a interpelação ideológica como ritual supõe reconhecer que não há ritual sem falha; enfraquecimento e brechas, 'uma palavra por outra' é a definição da metáfora, mas é também o ponto em que o ritual se estilhaça no lapso (e o mínimo que se pode dizer é que os exemplos são abundantes, seja na cerimônia religiosa, no processo jurídico, na lição pedagógica ou no discurso político...).

A brecha no ritual ideológico possibilita entrever que o funcionamento do discurso jornalístico não pôde capturar e apagar a potência do acontecimento discursivo que foi a publicação de Quarto de Despejo. A força da escrita de Carolina inaugura discursividades; ela influenciou uma geração de escritoras, militantes e intelectuais que passam a atuar nas décadas subsequentes, ancoradas nas filiações de memória que Carolina e o acontecimento de seu livro possibilita.

\section{CONSIDERAÇÕES FINAIS}

Neste artigo, examinamos o funcionamento das designações em um corpus constituído por recortes de notícias veiculadas na imprensa brasileira no ano de lançamento de Quarto de Despejo: o diário de uma favelada.

Quarto de Despejo passa a funcionar como referência básica no imaginário constitutivo do Brasil, estabilizando-se como fundamental na construção da memória dos movimentos das mulheres negras. Um discurso fundador. Entretanto, como nos mostrou Orlandi (1992), o discurso fundador não diz respeito a um princípio absoluto; os sentidos não têm origem determinada. Ele, o discurso fundador, funciona em função de uma relação de forças que transfigura o sem-sentido em 
sentido. Carolina permite que determinados sentidos sobre as mulheres negras possam emergir na imprensa brasileira, deslocando o já-dito; seu livro, em sua dimensão de acontecimento, significa o sem-sentido, dá lugar a lugares interditados pelos processos de significação.

A potência de acontecimento de Carolina e Quarto de Despejo consiste na produção de filiações de memória que se atualizam pelas lacunas dos sentidos hegemônicos. É nesse ínterim, pelas brechas, que o acontecimento se coloca e é possível uma outra discursividade que tem em Carolina e Quarto de Despejo uma ruptura. Consideramos que essa ruptura estabelece uma discursividade e é isso que os caracteriza em relação à historicidade. "O discurso fundador se faz em uma relação de conflito com o processos de produção dominante de sentidos, aí produzindo uma ruptura, um deslocamento" (ORLANDI, 1992, p. 24).

É partir do discurso fundador, como considera Orlandi, que se "[...] instalam as condições de formação de outros [sentidos], filiando-se à sua própria possibilidade, instituindo em seu conjunto um complexo de formações discursivas, uma região de sentidos, um sítio de significância [...]". Nesse limiar é que consideramos Carolina Maria de Jesus como a possibilidade de um novo sentido, uma vez que Quarto de Despejo inaugura uma discursividade. A designação "escritora negra", posta em circulação na imprensa em 1960, indicia uma nova maneira para significar as mulheres negras, inaugura para elas um lugar de enunciação de sujeitas negras escritoras.

\section{REFERÊNCIAS}

BACCEGA, Maria Aparecida; AZEVEDO, Aline Fernandes de. O discurso hegemônico de Veja e a construção da imagem do pobre. Comunicaçao \& Educação, ano XII, n 1 , jan/ abr. 2007.

BAIRROS, Luiza. Lembrando Lélia Gonzalez (1994). Afroasia, Salvador, n. 23, 2000. Disponível em: <https://institutoodara.org.br/public/lembrando-lelia-gonzalez-1994luizabairros/>.

BOCCHI, Aline Fernandes de Azevedo. Corpos contraditores e o inapreensivel do sexo, do gênero e da sexualidade. In: GARCIA, Dantielli Assumpção; BIZIAK, Jacob dos Santos; SOUSA, Lucília Maria Abrahao (orgs.). Do cárcere à invençao: gêneros sexuais na contemporaneidade. São Carlos: Pedro e João, 2017a.

BOCCHI, Aline Fernandes de Azevedo. Sexualidades marginais e subversões de gênero em Madame Satã. In: SOARES, Alexandre Sebastião Ferrari; GARCIA, Dantielli Assumpção 
2017. Inquietações de gêneros e sexualidades: leituras na contemporaneidade. Porto Alegre: Evangraf, 2017.

BOCCHI, Aline Fernandes de Azevedo. (A)versões ao/do corpo negro feminino em Mulheres Detentas, de João do Rio. In: JESUS, Danie Marcelo de; MELO, Glenda Cristina Valim de; et all (orgs.) Corpos transgressores: políticas de resistências. Campinas: Pontes Editores, 2018.

BOCCHI, Aline Fernandes de Azevedo. Da senzala ao cárcere: corpo e maternidade às margens da história. Fragmentum, Santa Maria, v. 54, p. 135-244, jul./dez. 2019.

BURANELLI, Gabriela Moreira. As formulações para Carolina Maria de Jesus e Quarto de Despejo: interpretação e efeitos de sentido das designações em manchetes de jornais. 2021. 70f. Dissertação (Mestrado em Linguística) - Programas de Pós-Graduação em Linguística, Universidade de Franca, Franca, 2021.

CARNEIRO, Sueli. Enegrecer o Feminismo: a situação da mulher negra na américa latina a partir de uma perspectiva de gênero. 2011. Disponível em: <https://www.geledes. org.br/ enegrecer-o-feminismo-situacao-da-mulher-negra-na-americalatinapartir-deumaperspectiva-de-genero/>. Acesso em: 10 abr. 2021.

CESTARI, Mariana Jafet. Vozes-mulheres negras ou feministas e antirracistas graças às Yabás. 2015. 264f. Tese (Doutorado em Linguística) - Instituto de Estudos da Linguagem, Universidade Estadual de Campinas, Campinas, 2015.

GARCIA, Dantielli Assumpção; ABRAHÃO E SOUSA, Lucília Maria. "Somos todxs Cláudia": a legitimação da violência pelo Estado. Linguagem em (Dis)curso - LemD, Tubarão, SC, v. 15, n. 1, p. 47-59, jan./abr. 2015.

GONZALES, Lélia. Por um feminismo afro-latino-americano: ensaios, intervenções e diálogos. Organização Flavia Rios, Maria Lima. $1^{\circ}$ ed, Rio de Janeiro: Zahar, 2020.

GUIMARÃES, Eduardo. Designação e espaço de enunciação: um encontro político no cotidiano. Revista Letras, n. 26, p.53-62, 2003. Disponível em: <http://w3.ufsm.br/ revistaletras/ artigos_r26/artigo_5.pdf>. Acesso em: 10 abr. 2021.

HOOKS, bell. Mulheres Negras: moldando a teoria feminista. Revista Brasileira de Ciência Política, Brasília, n.16, pp.193-210, jan/abr. 2015.

MARIANI, Bethania. Nome próprio e Constituição do Sujeito. Letras, Santa Maria, v. 24, n. 48, p. 131-141, jan./jun. 2014. Disponível em: <https://periodicos.ufsm.br/letras/ article/view/14428> Acesso em: 11 jan. 2020.

MUNHOZ, Neuzer; SCHONS, Carme. (2015). O processo de autoria e as posições discursivas na escrita revolucionária. Revista Desenredo, 11(1). 2015. Disponível em: <https://doi.org/10.5335/rdes.v11i1.4954>. Acesso em 11 fev. 2021.

ORLANDI, Eni Puccinelli. (org.) Discurso fundador. Campinas, S. R: Pontes, 1992. 
ORLANDI, Eni. Puccinelli Terra à vista. Discurso do confronto: velho e novo mundo. Campinas: Editora da Unicamp, 2008.

ORLANDI, Eni. Puccinelli. Paráfrase e polissemia: a fluidez nos limites do simbólico. RUA, Campinas, SP, v.4, n.1, p. 9-20, 1998. Disponível em: <https://periodicos.sbu. unicamp.br/ ojs/index.php/rua/article/view/8640626>. Acesso em: 11 fev. 2021.

ORLANDI, Eni. Puccinelli. Interpretação: autoria, leitura e efeitos do trabalho simbólico. 5. ed. Campinas (São Paulo): Pontes, 2007.

ORLANDI, Eni Puccinelli. Discurso e texto: formulação e circulação dos sentidos. Campinas: Pontes, 2001.

ORLANDI, Eni Puccinelli. Análise de discurso: princípios e procedimentos. 13. ed. Campinas, SP: Pontes, 2020.

PAVEAU, Marie-Anne. Le discours des vulnérables. Proposition théorique et politique. Cadernos De Linguagem e Sociedade, 18(1), 135-157, 2017. Disponível em: <https:// doi.org/10.26512/les.v18i1.1571>.

PÊCHEUX, Michel. Semântica e discurso: uma crítica à afirmação do óbvio. Tradução Bot. Pucinelli, Orlandi [et al.]. 2. ed. Campinas-SP: Editora da Unicamp. 1995.

PÊCHEUX, Michel. "Papel da memória". In: ACHARD, P. et al. (Org.). Papel da memória. Campinas: Pontes Editores, 1983.

RODRIGUES, Carla. Leiam Lélia Gonzales. Revista Cult, 2020. Disponível em: <https:// revistacult.uol.com.br/home/leiam-lelia-gonzalez/>.

SPIVAK, Gayatri Chakravorty. Pode o subalterno falar? Tradução de Sandra Regina Goulart Almeida, Marcos Pereira Feitosa, André Pereira Feitosa. Belo Horizonte: Editora UFMG, 2010.

ZOPPI-FONTANA, Mônica. Identidades (In)formais: contradição, processos de designação e subjetivação na diferença. ORGANON, v. 17, n. 35, 2003. DOI: <https:// doi.org/10.22456/2238-8915.30027>. Disponível em: <https://seer.ufrgs.br/organon/ article/view/30027>.

ZOPPI-FONTANA, Mônica; CESTARI, Marians Jafet. Cara de empregada doméstica: Discursos sobre os corpos de mulheres negras no Brasil. RUA, Campinas, SP, v. 20, p. 167-185, 2015. DOI: 10.20396/rua.v20i0.8638265. Disponível em: <https://periodicos. sbu.unicamp.br/ojs/index.php/rua/article/view/8638265>. Acesso em: 10 abr. 2021.

RECEBIDO EM: 27/05/2021

ACEITE EM: 07/06/2021 